\section{Septic arthritis and hemarthroses caused by Haemophilus influenzae serotype $A$ in children}

\author{
Ravi S. Samraj, ${ }^{1}$ Jaime Fergie ${ }^{2}$ \\ 'Division of Pediatric Critical Care, \\ Shands Children's Hospital, UF Health, \\ Gainesville, FL; ${ }^{2}$ Pediatric Infectious \\ Disease, Driscoll Children's Hospital, \\ Corpus Christi, TX, USA
}

\begin{abstract}
Invasive disease caused by Haemophilus influenzae serotype A (Hia) is rare in children. Clinical syndromes caused by Hia include meningitis, sepsis and respiratory tract infections. Septic arthritis is rare in children with invasive Hia infection and hemarthrosis has not been described in the published literature. We report a case of septic arthritis and hemarthrosis caused by Hia infection in a 2.5 year-old-boy and review invasive Hia infection in children.
\end{abstract}

\section{Introduction}

Haemophilus influenzae is not an uncommon pediatric pathogen. Previously $H$. influenzae type b (Hib) was the predominant pathogen, however there has been a shift in the serotype prevalence since the introduction of the $H$. influenzae type B vaccine in the early 1990s. Serotypes, other than Hib, reported to cause disease include serotype A, C, D, E and F.

Prevalence of $H$. influenzae serotype a (Hia) has been reported to be higher in the post vaccination era. ${ }^{1,2}$ Outbreaks have been reported in the aboriginal populations of Canada, United States and Australia..$^{3-5}$ Reported clinical infections caused by Hia include meningitis, pneumonia, cellulitis, pericarditis and sepsis. ${ }^{1,2,6,7}$ Joint involvement is rare in Hia infection and hemarthrosis, to the best of our knowledge, has not been reported. Hia septic arthritis responds well to antibacterial therapy and does not appear to result in significant local tissue damage.

\section{Case Report}

A previously healthy 2.5 -year-old boy presented to our hospital with a 2 day history of left knee pain, refusal to bear weight and sub- jective fever. There was a history of fall 2 days prior and preceding URI symptoms 5 days prior. No recent history of diarrhea, exanthem, bleeding, recent travel, animal exposure, tick bites, myalgia, weight loss, family history of arthritis or bleeding disorders. Immunizations were up to date including complete series of Hib vaccine. Physical examination was significant for a swollen, warm and tender left knee with limitation of active and passive movement. He was afebrile at admission and rest of the physical exam was unremarkable. Laboratory studies revealed a white blood cell count of $11,000 / \mathrm{mm}^{3}$, erythrocyte sedimentation rate of $44 \mathrm{~mm} / \mathrm{hr}$ and $\mathrm{C}$ reactive protein of $25 \mathrm{mg} / \mathrm{L}$. X-ray of the left knee did not reveal fracture or osteomyelitis. An ultrasound revealed knee effusion. He was started on intravenous clindamycin. Joint aspiration yielded $14 \mathrm{~mL}$ of bloody fluid. Arthrotomy was not done at this time as the operating surgeon did not suspect septic arthritis. Coagulation studies were within normal limits. Culture of the joint fluid grew $2+H$. influenzae, beta lactamase negative. Antibiotic was changed to ampicillin. A three phase nuclear medicine bone scan was normal.

Arthrotomy 2 days later obtained purulent fluid. Fluid analysis showed 2+ WBCs and 4+ RBCs. The initial $\mathrm{H}$ influenzae isolate from the joint aspirate was identified as Haemophilus influenzae serotype a, biotype II by Texas State Health Services Laboratory in Austin. Blood cultures were negative after 5 days of incubation.

There was resolution of the fever with marked improvement in arthritis. Drain was removed after 2 days and he was discharged on hospital day 6 on 2 weeks of oral amoxicillin. Follow up at 3 weeks showed normal exam and a normal knee X-ray.

\section{Discussion}

Encapsulated Haemophilus influenzae is a common pediatric pathogen. Apart from type B, other serotypes include A, C, D, E and F. In addition non-typeable isolates have been identified. Following the introduction of Hib vaccination, the incidence of disease caused by Hib has decreased to 0.30 per 100,000 children less than 5 years in the United States in 2008.

Hia accounted for less than $1 \%$ of invasive Haemophilus influenzae disease among all age groups in a United States study across six states in $1986 .{ }^{9}$ However later studies have found it to be more common in some populations. In the post vaccine era, Hia accounted for half of the isolates from patients with invasive Haemophilus influenzae disease in a five year study conducted between January 2000 and December 2004 in a province of Manitoba,
Correspondence: Ravi Samraj, Division of Pediatric Critical Care, Shands Children's Hospital, 1600 SW Archer Rd., Gainesville, FL 32608 , USA.

Tel.: + 1.352.265.0462 - Fax: +1.352.265.0443.

E-mail: ravisamraj@gmail.com

Key words: Haemophilus influenzae serotype A; Septic arthritis; Hemarthrosis; Children.

Contributions: the authors contributed equally.

Conflict of interest: the authors declare no potential conflict of interest.

Received for publication: 3 March 2016. Revision received: 13 April 2016.

Accepted for publication: 15 April 2016

This work is licensed under a Creative Commons Attribution-NonCommercial 4.0 International License (CC BY-NC 4.0).

(C) Copyright R.S. Samraj and J.Fergie, 2016 Licensee PAGEPress, Italy

Infectious Disease Reports 2016; 8:6494

doi:10.4081/idr.2016.6494

Canada. ${ }^{1}$ Hia is now the most common among typeable Haemophilus influenzae isolates in the North American Arctic; the highest rates are among indigenous children population. ${ }^{2}$ In this study, the incidence of Hia infection (2002-2011) among children $<5$ years was 5.4/100,000; 27 cases occurred in Alaska Native children $(18 / 100,000)$ versus 2 cases in nonnative children $(0.5 / 100,000)$. In an outbreak of Hia infection between 2009-2011 (13 cases), the same study group found that there was 1 death (case-fatality ratio $8 \%$ ) and primary clinical conditions included meningitis $(n=6)$, pneumonia with bacteremia $(n=3)$, septic arthritis $(\mathrm{n}=2)$, cellulitis $(\mathrm{n}=1)$, and bacteremia $(n=1)$. They concluded that since introduction of the Hib conjugate vaccine, Hia infection has become a major invasive bacterial disease in Alaskan native children. Outbreaks of Hia invasive infections have been reported in the pediatric population. Ribeiro et al. noted that the incidence of Hib meningitis decreased by $69 \%$ during the first year following initiation of Hib conjugate immunization, while the incidence of Hia meningitis increased eightfold in Brazil. ${ }^{10}$ Although meningitis is the most common invasive disease caused by $\mathrm{Hia}$, it has also been recovered from blood, ${ }^{1,2}$ cellulitis,${ }^{6}$ respiratory tract, ${ }^{7}$ pleural fluid and pericardial fluid. ${ }^{2}$ Ulanova et al. recently reviewed invasive Hia infection and discuss its global epidemiology, clinical presentation, microbiology, immunology, prevention, and control. ${ }^{5}$

Joint involvement is rarely reported in literature as a manifestation of invasive Hia dis- 
Table 1. Haemophilus influenzae A septic arthritis in children.

\begin{tabular}{|c|c|c|c|c|c|c|c|}
\hline Author & $\begin{array}{l}\text { Geographical } \\
\text { location }\end{array}$ & Age, sex & Presentation & $\begin{array}{l}\text { Other disease } \\
\text { conditions }\end{array}$ & $\begin{array}{l}\text { Source of } \\
\text { organism } \\
\text { isolation }\end{array}$ & $\begin{array}{l}\text { Organism } \\
\text { characteristic }\end{array}$ & Outcome \\
\hline $\begin{array}{l}\text { Hammitt et al. } \\
(2005)^{9}\end{array}$ & Alaska, USA & $8 \mathrm{~m}, \mathrm{M}$ & Septic arthritis & $\begin{array}{l}\text { History of } \\
\text { pyelonephritis }\end{array}$ & $\begin{array}{l}\text { Blood, } \\
\text { synovial } \\
\text { fluid }\end{array}$ & $\begin{array}{l}\beta \text {-lactamase- } \\
\text { negative }\end{array}$ & $\begin{array}{l}\text { Complete } \\
\text { recovery, } \\
\text { 2nd episode of } \\
\text { arthritis after } 3\end{array}$ \\
\hline $\begin{array}{l}\text { months } \\
\text { Kapogiannis et al. } \\
(2005)^{10}\end{array}$ & Georgia, USA & $30 \mathrm{~m}, \mathrm{M}$ & $\begin{array}{l}\text { Septic arthritis, } \\
\text { meningitis }\end{array}$ & None & $\begin{array}{l}\text { Blood, CSF, } \\
\text { synovial fluid }\end{array}$ & $\begin{array}{l}\beta \text {-lactamase- } \\
\text { negative }\end{array}$ & $\begin{array}{l}\text { Recovery } \\
\text { from arthritis } \\
\text { + neuro cognitive } \\
\text { deficits }\end{array}$ \\
\hline $\begin{array}{l}\text { de Almeida et al. } \\
(2008)^{12}\end{array}$ & $\begin{array}{l}\text { Rio de Janeiro, } \\
\text { Brazil }\end{array}$ & $3 y, F$ & Septic arthritis & None & Synovial fluid & $\begin{array}{l}\beta \text {-lactamase- } \\
\text { positive }\end{array}$ & Complete recovery \\
\hline Fischer $(2013)^{11}$ & Central Australia & $9 \mathrm{~m}, \mathrm{M}$ & Septic arthritis & None & $\begin{array}{l}\text { Synovial fluid, } \\
\text { blood }\end{array}$ & $\beta$-lactamase-negative & Complete recovery \\
\hline Our patient & Texas, USA & $2.5 \mathrm{y}, \mathrm{M}$ & Septic arthritis & None & Synovial fluid & $\beta$-lactamase-negative & Complete recovery \\
\hline
\end{tabular}

m, months; y, year; F, female; M, male; CSF, cerebrospinal fluid.

ease. There are only 2 studies of outbreaks of invasive Hia infection where septic arthritis has been described. The first study was in the North American arctic population. ${ }^{2}$ However, the most common presentation in the above mentioned study was meningitis and pneumonia. In a second study, Hammitt et al. in 2003 described a small outbreak of invasive Hia disease involving 3 infants in Alaska. In their study, an 8 month old infant developed 2 episodes of septic arthritis in a period of 3 months. ${ }^{11}$ This patient responded well to ceftriaxone and amoxicillin-clavulanate therapy. There are 3 isolated case reports of septic arthritis caused by Hia infection in children. Kapogiannis reported a case of septic arthritis in a 30 month old boy associated with meningitis. ${ }^{12}$ More recently, the first case of Hia septic arthritis in Australia and the first case in Brazil were reported. ${ }^{13,14}$ In both cases, Hia septic arthritis seems to respond well to antibacterial therapy and does not seem to leave behind any sequelae (as in our patient). Cases reported so far have been summarized below (Table 1). Few studies have looked at the Hia carriage rates in the general population. Rates of $<1 \%$ to $3.5 \%$ have been reported from South American and Australian aboriginal population. ${ }^{15-17}$ On the contrary, high prevalence (16$45 \%$ ) of carriage rates have been reported in close contacts of children with invasive Hia disease in Alaska. ${ }^{11,18}$ Recent serological studies among aboriginals in Ontario showed high levels of anti-Hia IgM compared to IgG in contrast to anti-Hib levels (IgG levels higher than IgM) providing evidence to the recent increase in the Hia prevalence in the community. Hia infection rate in young children in northern Canada is now above the rate observed in the general population when the Hib vaccine was introduced. ${ }^{15}$ Efforts are ongoing to develop a suitable vaccine against Hia. ${ }^{19}$

\section{Conclusions}

Our case is unique in that it is the first reported case of hemarthrosis caused by Hia and a rare case of Hia septic arthritis in the non-Alaskan United States pediatric population. Our report highlights the fact that Hia has potential to cause invasive infections in the post Hib vaccination era and the need for constant surveillance and clinical suspicion to diagnose Hia invasive infections. Prognosis appears to be good as the infection responds well to appropriate antibacterial therapy. Further research and developments in the field of immune-prophylaxis and chemoprophylaxis are warranted.

\section{References}

1. Tsang RS, Mubareka S, Sill ML, et al. Invasive Haemophilus influenzae in Manitoba, Canada, in the postvaccination era. J Clin Microbiol 2006;44:1530-5.

2. Bruce MG, Zulz T, DeByle C, et al. Haemophilus influenzae serotype a invasive disease, Alaska, USA, 1983-2011. Emerg Infect Dis 2013;19:932-7.

3. Tsang RS, Bruce MG, Lem M, et al. A review of invasive Haemophilus influenzae disease in the indigenous populations of North America. Epidemiol Infect 2014;142:1344-54.

4. Rotondo JL, Sherrard L, Helferty M, et al. The epidemiology of invasive disease due to Haemophilus influenzae serotype a in the Canadian North from 2000 to 2010. Int J Circumpolar Health 2013;72.

5. Ulanova M, Tsang RS. Haemophilus influenzae serotype a as a cause of serious invasive infections. Lancet Infect Dis 2014;14:70-82.

6. Molougney B, Ruthnum P, Chan E. Case reports: invasive Haemophilus influenzae type a infections. Can Commun Dis Rep 1997;23:82-4.

7. Holdaway MD, Turk DC. Capsulated Haemophilus influenzae and respiratorytract disease. Lancet 1967;1:358-60.

8. Centers for Disease Control and Prevention. Active bacterial core surveillance report. Emerging Infections Program Network. Haemophilus influenzae. 2011. Available from: http://www.cdc.gov/abcs/ reports-findings/survreports/hibl1.pdf.

9. Wenger JD, Pierce R, Deaver K, et al. Invasive Haemophilus influenzae disease: a population-based evaluation of the role of capsular polysaccharide serotype. Haemophilus Influenzae Study Group. J Infect Dis 1992;165:S34-5.

10. Ribeiro GS, Reis JN, Cordeiro SM, et al. Prevention of Haemophilus influenzae type b (Hib) meningitis and emergence of serotype replacement with type a strains after introduction of Hib immunization in Brazil. J Infect Dis 2003;187:109-16.

11. Hammitt LL, Block S, Hennessy TW, et al. Outbreak of invasive Haemophilus influenzae serotype a disease. Pediatr Infect Dis J 2005;24:453-6.

12. Kapogiannis BG, Satola S, Keyserling HL, Farley MM. Invasive infections with Haemophilus influenzae serotype a containing an IS1016-bexA partial deletion: possible association with virulence. Clin Infect Dis 2005;41:e97-103.

13. Fischer NJ. Haemophilus influenzae serotype a septic arthritis in an immunized central Australian indigenous child. Int J Infect Dis 2014;21:15-6. 
14. de Almeida AE, Schroeder LF, Caldeira NG, et al. Septic arthritis due to Haemophilus influenzae serotype a in the post-vaccination era in Brazil. J Med Microbiol 2008;57:1311-2.

15. Boisvert AA, Moore D. Invasive disease due to Haemophilus influenzae type A in children in Canada's north: a priority for prevention. Can J Infect Dis Med Microbiol 2015;26:291-2.

16. de Carvalho CX, Kipnis A, Thorn L, et al.
Carriage of Haemophilus influenzae among Brazilian children attending day care centers in the era of widespread Hib vaccination. Vaccine 2011;29:1438-42.

17. Gratten M, Manning K, Dixon J, et al. Upper airway carriage by Haemophilus influenzae and Streptococcus pneumoniae in Australian aboriginal children hospitalised with acute lower respiratory infection. Southeast Asian J Trop Med Public Health 1994;25:123-31.
18. Hammitt LL, Hennessy TW, RomeroSteiner S, Butler JC. Assessment of carriage of Haemophilus influenzae type a after a case of invasive disease. Clin Infect Dis 2006;43:386-7.

19. Desai S, Tsang R, St Laurent M, Cox A. Collaboration on a public health driven vaccine initiative. Can Commun Dis Rep 2014;40:365-8. 